\title{
Reply to the letter "Mean platelet volume as a surrogate marker of inflammation in systemic lupus erythematosus"
}

\author{
Sevgi Yavuz • Aydın Ece
}

Received: 16 March 2014 / Revised: 20 March 2014 / Accepted: 22 March 2014 / Published online: 4 May 2014

(C) Clinical Rheumatology 2014

Dear Editor,

We thank Varol and Ozaydın for their comments related to our article "Mean platelet volume as an indicator of disease activity in juvenile SLE." We agree with the authors that detailed information was not given in the methodology of the mean platelet volume (MPV). In our study, all samples were taken into the tubes with EDTA, and complete blood cell counts were measured within $1 \mathrm{~h}$ after venipuncture. Thus, the measuring time for MPV seemed to be appropriate as stated to be less than $2 \mathrm{~h} \mathrm{[1].} \mathrm{On} \mathrm{the} \mathrm{other} \mathrm{hand,} \mathrm{recent} \mathrm{reports} \mathrm{indicated} \mathrm{a}$ link among MPV, obesity, and metabolic syndrome [2, 3]. However, none of our study participants had a proven metabolic syndrome. The mean body mass index values were not significantly different between study groups $(20.2 \pm 2.9$ in patients and $19.8 \pm 3.1$ in control groups, respectively; $p=$ $0.51)$. Since MPV has been introduced as a novel marker of cardiovascular disease $[3,4]$, we also examined the patients by echocardiography and found normal indices. However, we did not put this data on the article as the primary aim was to assess the relationship between MPV and disease activity of SLE, not the cardiovascular risk in those patients. Furthermore, in agreement with the authors, we consider that cardiovascular and additional inflammatory risk factors should be taken into account while assessing MPV in patients, particularly in adults.

Conflict of interest None.

\section{References}

1. Lancé MD, van Oerle R, Henskens YM, Marcus MA (2010) Do we need time adjusted mean platelet volume measurements? Lab Hematol $16: 28-31$

2. Kutlucan A, Bulur S, Kr S, Bulur S, Önder E, Aslantaş Y, Ekinözü İ, Aydın Y, Özhan H (2012) The relationship between mean platelet volume with metabolic syndrome in obese individuals. Blood Coagul Fibrinolysis 23:388-390

3. Vizioli L, Muscari S, Muscari A (2009) The relationship of mean platelet volume with the risk and prognosis of cardiovascular diseases. Int J Clin Pract 63:1509-1515

4. Sun X, Jia Z (2012) A brief review of biomarkers for preventing and treating cardiovascular diseases. J Cardiovasc Dis Res 3:251-254
S. Yavuz $(\bowtie) \cdot$ A. Ece

Division of Pediatric Nephrology, Dicle University School of

Medicine, 21080 Diyarbakır, Turkey

e-mail: drsyavuz@gmail.com 